Check for updates

Cite this: RSC Adv., 2019, 9, 14154

Received 4th March 2019

Accepted 1st May 2019

DOI: $10.1039 / c 9 r a 01608 b$

rsc.li/rsc-advances

\section{Highly dispersed Ni nanoparticles on mesoporous silica nanospheres by melt infiltration for transfer hydrogenation of aryl ketones $\uparrow$}

\author{
Hyemin Kweon, $\ddagger^{\mathrm{a}}$ Sanha Jang, $\ddagger^{\mathrm{a}}$ Akerke Bereketova, ${ }^{a} \mathrm{Ji}$ Chan Park (D) *b \\ and Kang Hyun Park (D) *a
}

\begin{abstract}
Nickel-based catalysts have been applied to the catalytic reactions for transfer hydrogenation of carbonyl compounds. In the present work, highly dispersed nickel particles located at the pores of mesoporous silica spheres $(\mathrm{NiamSiO})$ were prepared via an optimized melt infiltration route. The nickel nanoparticles of $10 \mathrm{wt} \%$ in the $\mathrm{NiamSiO} 2$ catalyst could be uniformly loaded with high dispersion of $36.3 \%$, resulting excellent performance for catalytic transfer hydrogenation of aryl ketones.
\end{abstract}

The reduction of carbonyl compounds has received steady interest as a common transformation in organic synthetic chemistry. Corresponding alcohols are important building blocks for the manufacture of chemicals, pharmaceuticals, and cosmetics. ${ }^{1,2}$ The transfer hydrogenation $(\mathrm{TH})$ reaction of ketones has lots of advantages owing to its low cost, simple process, easy handling, and mild conditions. ${ }^{3}$ Isopropyl alcohol both as a solvent and hydrogen donor provides safe reaction conditions. ${ }^{4}$ Until now, many catalysts have been developed for $\mathrm{TH}$ reactions. ${ }^{5}$

Among the catalysts for $\mathrm{TH}$ reactions, nickel-based catalysts are representative, due to the metallic nickel surface can absorbs hydrogen and easily activates hydrogen in the atomic state. ${ }^{6-11}$ In addition, nickel compounds could be the significant catalyst candidate because of the low price, accessibility, and high reactivity. ${ }^{12,13}$ Therefore, several works used nickel nanocatalysts for TH reactions. ${ }^{14-17,44-51}$ However, developing the new supported catalyst with the high metal dispersion and narrow particle size distribution is still required, because it can enhance the reactant conversion and improve product yield. ${ }^{18}$ Recently, melt infiltration process has been exploited to prepare supported nanocatalysts as a fast and convenient route with no solvent use. ${ }^{19-21}$

The method which uses highly porous supports with regular porosity and hydrated metal salts with mild melting temperatures, allowed the metal salts to permeate inside the porous support via capillary forces. High performance nanocatalysts based on well-dispersed nanoparticles could be obtained through uniform infiltration of metal precursors and sequential thermal

\footnotetext{
${ }^{a}$ Department of Chemistry, Pusan National University, Busan, 46241, Korea. E-mail: chemistry@pusan.ac.kr

${ }^{b}$ Clean Fuel Laboratory, Korea Institute of Energy Research, Daejeon, 34129, Korea. E-mail:jcpark@kier.re.kr

$\dagger$ Electronic supplementary information (ESI) available. See DOI: 10.1039/c9ra01608b

\$ These authors contributed equally to this work.
}

treatment. $^{22}$ The obtained nanoparticles have narrow size distributions as well as small sizes, enlarging active sites. ${ }^{23,24}$

Mesoporous silica nanosphere $\left(\mathrm{mSiO}_{2}\right)$ as a porous support can be an outstanding platform for the synthesis of metal nanoparticle, owing to the good thermal stability, high surface area, and large pore volume as well as uniform pore structures. ${ }^{25-29}$ Herein, we report a new catalyst with highly dispersed $\mathrm{Ni}$ nanoparticles at mesoporous silica sphere nanostructures (Ni@ $\mathrm{mSiO}_{2}$ ) for catalytic $\mathrm{TH}$ reactions, which was synthesized through a melt infiltration of hydrated nickel salts and a sequential thermal reduction (Scheme 1). First, $\mathrm{mSiO}_{2}$ supports could be prepared by a sol-gel method based on a modified Stöber process. More details were described in the ESI. $\dagger$ The mesopores were formed in the silica nanospheres using the cationic surfactant $\mathrm{C}_{16}$ TAB as a self-assembly template. The TEM images show mesoporous silica spheres with an average diameter of $417 \pm 20 \mathrm{~nm}$ (Fig. 1a and b). Ordered mesoporous channels were generated by removing the long carbon chains of $\mathrm{C}_{16} \mathrm{TAB}$ by calcination at $500{ }^{\circ} \mathrm{C}$. The corresponding Fourier-transform (FT) pattern showed a ring pattern of polycrystalline (inset of Fig. 1c). The inverse fast Fourier-transform (IFFT) image, calculated by Micrograph TM Gatan software, also demonstrated the existence of hexagonal lattice planes (Fig. 1c).

The brightest of the rings originated from a two-dimensional hexagonal ( $p 6 \mathrm{~mm}$ ) structure with $d 100$ spacing. The interplanar spacing computed from the brightest FFT diffraction ring was approximately $3 \mathrm{~nm}$, corresponding to the pore sizes shown in the TEM image (Fig. 1d).

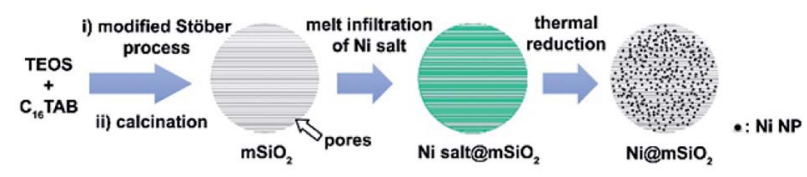

Scheme 1 A brief synthetic scheme of $\mathrm{NiamSiO}$, nanocatalyst. 


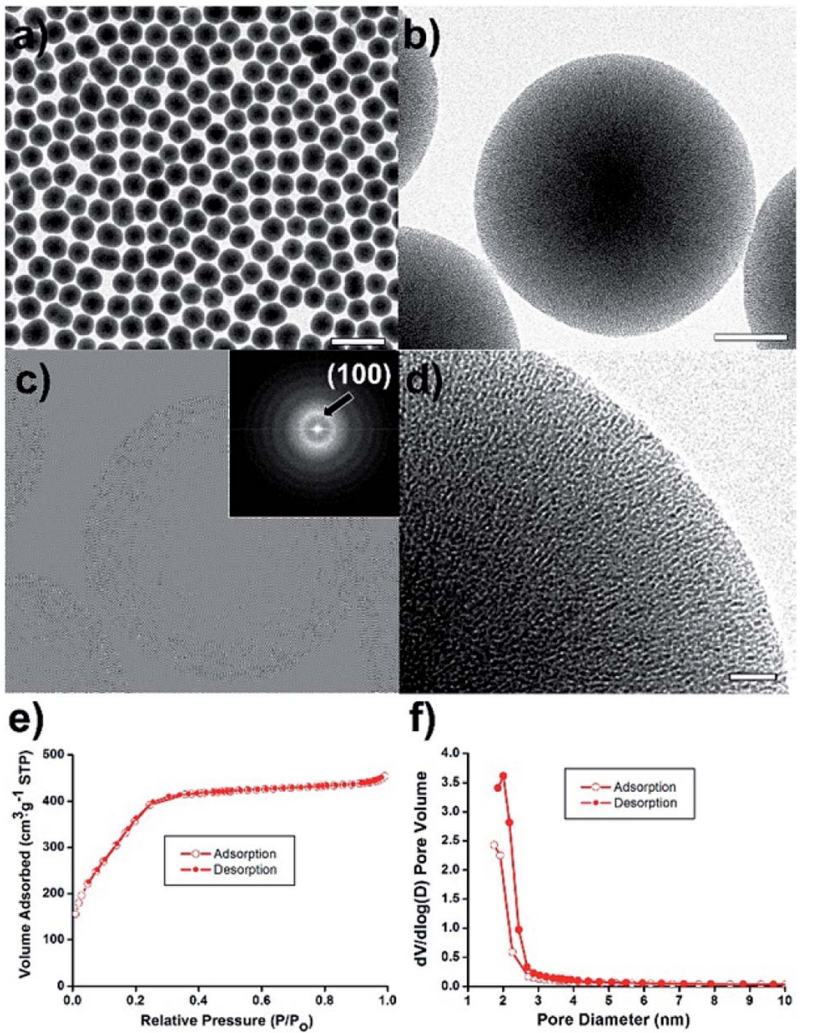

Fig. 1 (a and b) TEM images, (c) FT pattern for (b) (inset of c) and IFFT image, (d) HRTEM image, (e) $\mathrm{N}_{2}$ adsorption/desorption isotherms, and (f) pore size distribution diagrams of $\mathrm{mSiO}_{2}$. The bars represent $1 \mathrm{~mm}$ (a), $100 \mathrm{~nm}$ (b), and $20 \mathrm{~nm}$ (d).

$\mathrm{N}_{2}$ sorption experiments for the $\mathrm{mSiO}_{2}$ nanosphere exhibited type IV adsorption-desorption hysteresis with $\mathrm{H} 4$ type hysteresis loop (Fig. 1e). The Brunauer-Emmett-Teller (BET) surface area and pore volume of the $\mathrm{mSiO}_{2}$ nanosphere were $1501 \mathrm{~m}^{2}$ $\mathrm{g}^{-1}$ and $0.70 \mathrm{~cm}^{3} \mathrm{~g}^{-1}$, respectively. The average pore size was estimated to be approximately $2 \mathrm{~nm}$ from the adsorption/ desorption branches of $\mathrm{N}_{2}$ isotherms by using the BarrettJoyner-Halenda (BJH) method (Fig. 1f).

Scheme 1 illustrated the simple procedure for the synthesis of the Ni@mSiO ${ }_{2}$ nanocatalyst. Based on the small pore size $(3 \mathrm{~nm})$ of $\mathrm{mSiO}_{2}$ nanospheres, very tiny nickel nanoparticles $(\sim 2 \mathrm{~nm})$ could be generated via a melt-infiltration process and thermal treatment under hydrogen flow. Using a $0.55 \mathrm{~g}_{\text {nickel salt }} / \mathrm{g}_{\text {silica }}$ support ratio, the hydrated nickel salt (melting point $=56.7^{\circ} \mathrm{C}$ ) was successfully incorporated in the $\mathrm{mSiO}_{2}$ nanosphere during the melt infiltration process, driven by the capillary forces. The Ni-loading content after the final thermal treatment was calculated to be nominally $10 \mathrm{wt} \%$ on the basis of Ni converted from the nickel nitrate salt. First, the hydrated nickel salt was melt-infiltrated into the mesoporous silica pores of the $\mathrm{mSiO}_{2}$ nanospheres by physical mixing at room temperature with subsequent aging at $60^{\circ} \mathrm{C}$ for $24 \mathrm{~h}$ in a tumbling oven. Then, tiny nickel nanoparticles were generated by thermal reduction of the confined hydrated $\mathrm{Ni}$ salt in the small pores at $500{ }^{\circ} \mathrm{C}$ under hydrogen flow.

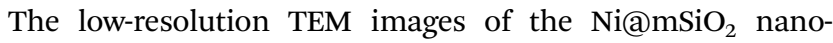
structure show Ni nanoparticles as black dots (Fig. 2a and b). The

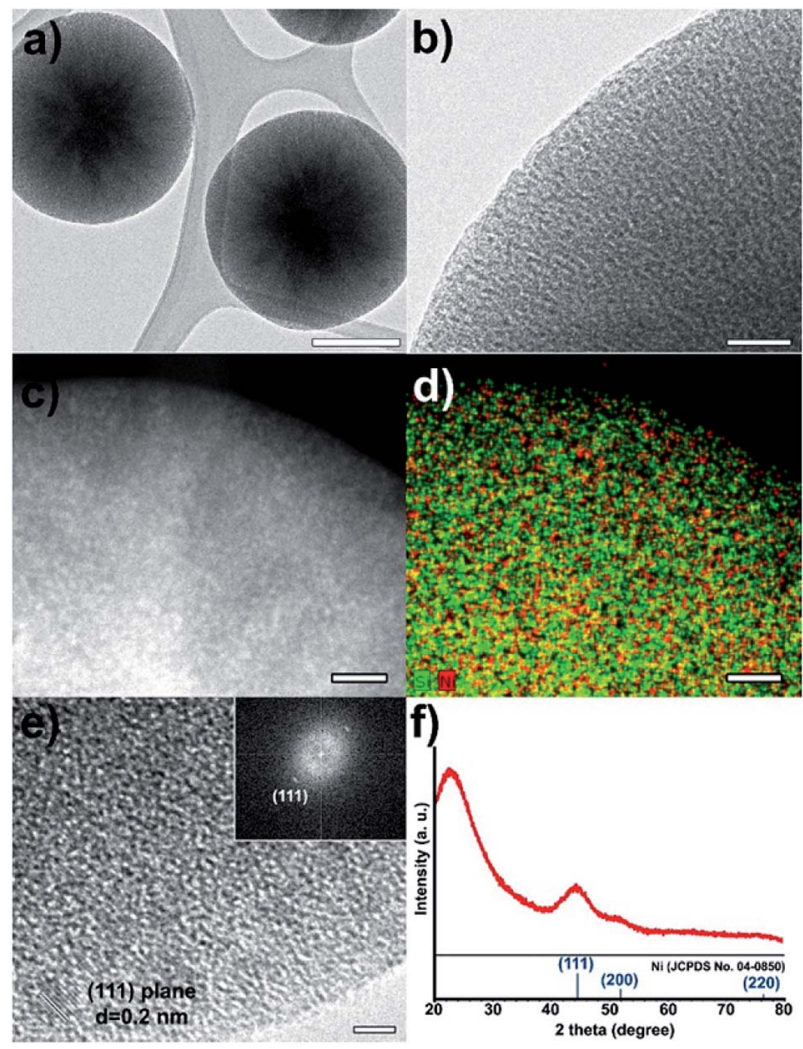

Fig. 2 (a and b) TEM and (c) HAADF TEM images, (d) scanning TEM image with elemental mapping and (e) HRTEM images, and (f) XRD spectrum of $\mathrm{Ni@mSiO}$ nanostructure. The bars represent $200 \mathrm{~nm}$ (a), $20 \mathrm{~nm}(\mathrm{~b}-\mathrm{d})$, and $2 \mathrm{~nm}(\mathrm{e})$.

high-angle annular dark-field scanning transmission electron microscopy (HAADF-STEM) image showed bright dots of a very small size (average $2.0 \mathrm{~nm}$ ), which indicates uniform incorporation of the Ni nanoparticles in the porous silica (Fig. $2 \mathrm{c}$ and S1 in the ESI $\dagger$ ). In the elemental mapping of silica (green color) and nickel (red color), high dispersion of nickel nanoparticles was observed (Fig. 2d). HRTEM analysis showed lattices of a single Ni nanoparticles in the $\mathrm{mSiO}_{2}$ pores (Fig. 2e). The inner particle size was observed to be around $2 \mathrm{~nm}$. The Fourier-transform pattern represented a single crystal of metallic nickel with a distance of $0.2 \mathrm{~nm}$ between neighboring fringes, which corresponded to the (111) planes of face centered-cubic nickel (Fig. 2e).

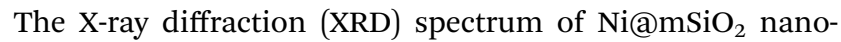
catalyst has a broad peak at $2 \theta=44.5^{\circ}$, which is assigned to the reflections of the (111) plane in the fcc-nickel phase (Fig. 2f, JCPDS No. 04-0850). The average crystal size of the nickel particle was estimated to be $1.8 \mathrm{~nm}$, from the broadness of the (111) peak using the Debye-Scherrer equation, which is wellmatched with that observed in the TEM images. The other intense peak around $23^{\circ}$ of the $\mathrm{Ni@mSiO}{ }_{2}$ nanocatalyst indicates the presence of amorphous silica.

Using a $\mathrm{H}_{2}$ chemisorption experiment, the active nickel surface area and average nickel particle size of the $\mathrm{Ni}_{0} \mathrm{mSiO}_{2}$ nanocatalyst could be analyzed, and measured $242 \mathrm{~m}^{2} \mathrm{~g}^{-1}$ and $2.78 \mathrm{~nm}$, respectively. The obtained Ni dispersion was very high, and was calculated to be $36.3 \%$. 


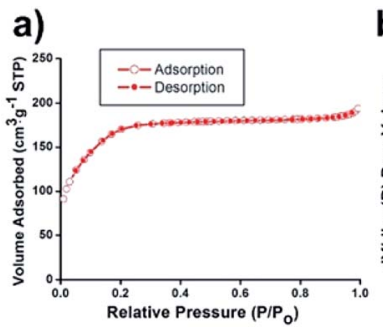

b)

Fig. 3 (a) $\mathrm{N}_{2}$ adsorption/desorption isotherms and (b) pore size distribution diagrams of $\mathrm{NiamSiO} 2$ nanocatalyst.

The XPS spectrum analysis was carried out to probe the

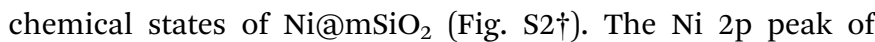

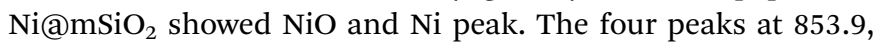
855.6, 860.7, and 863.5 eV are assigned to NiO, and the other peak at $852.1 \mathrm{eV}$ is assigned metallic $\mathrm{Ni}$ peak. The metallic $\mathrm{Ni}$ surface of the small nanoparticles $(\sim 2 \mathrm{~nm})$ was easily oxidized under an ambient condition.

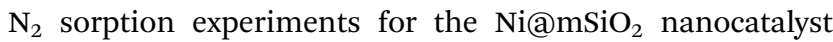
showed a type IV isotherm with type $\mathrm{H} 4$ hysteresis (Fig. 3a). The BET surface area was calculated to be $636 \mathrm{~m}^{2} \mathrm{~g}^{-1}$. The total pore volume was found to be $0.3 \mathrm{~cm}^{3} \mathrm{~g}^{-1}$, which is about $43 \%$ of the initial $\mathrm{mSiO}_{2}$ nanosphere $\left(0.7 \mathrm{~cm}^{3} \mathrm{~g}^{-1}\right)$. The significant decrease in pore volume was attributed to inner nickel nanoparticle occupancy. Applying the BJH method, small pore sizes were obtained by the adsorption/desorption branches (Fig. 3b). Because of the occupancy of tiny nickel particles in the pristine

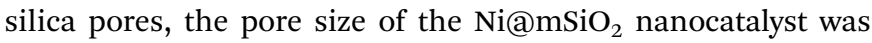
also slightly decreased, and was observed to be $1.8 \mathrm{~nm}$.

The Ni@ $\mathrm{mSiO}_{2}$ nanocatalyst was applied to the hydrogentransfer reaction of acetophenone. Acetophenone is an ideal substrate in the hydrogen transfer reaction, and is generally

Table 1 Catalytic transfer hydrogenation reactions of acetophenone by $\mathrm{NiamSiO}_{2}{ }^{a}$ used as a hydrogen acceptor. ${ }^{30}$ Among the various products of acetophenone reduction, only 1-phenylethanol resulted from the catalyzed reaction. The metallic $\mathrm{Ni}$ on the catalyst surface is the active species and the reaction was promoted by base. ${ }^{17}$ The dihydride species referred in this catalyst system to make alcohol from the transfer of the two hydrogen atoms of the donor to the surface of the metal. ${ }^{31}$ However, small amount of various byproduct including hemiacetals and condensation products which is occurred between ketone and alcohol were produced due to basic conditions. ${ }^{32}$ For optimization, the reaction parameters, such as amount of catalyst and base, temperature, and time, are adjusted. The TH reaction results of acetophenone are summarized in Table 1.

First, we studied the effect of the base and determined the amount of base required (Entries 3-6, Table 1). The reduction of acetophenone can be promoted by inorganic bases as the essential co-catalyst.

Alkaline bases enable increase in the concentration of the alkoxide ion and the deprotonation of the isopropyl alcohol coordinated to metal, which promotes the overall reaction. ${ }^{33,34}$ Although no reaction was observed without bases, a small amount of base was sufficient to trigger the reaction (Entry 5, Table 1). Subsequently, more than 1 equivalent of the base provided complete conversion efficiency of 1-phenylethanol (Entries 3, 4, Table 1) and 1 equivalent of base was sufficient to obtain high yield. Commercial nickel-aluminium alloy as a comparison catalyst showed lower conversion than that of

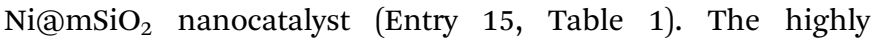

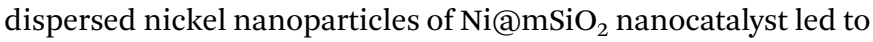
the increased activity.

The reaction temperature and time were also investigated. The reaction temperature was found to influence the reaction

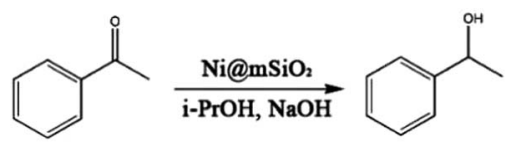

\begin{tabular}{|c|c|c|c|c|c|c|c|}
\hline Entry & Cat. (mol\%) & Temp. $\left({ }^{\circ} \mathrm{C}\right)$ & Time (min) & Base (eq.) & Conv. $^{b}(\%)$ & Yield $^{b}(\%)$ & TON \\
\hline 1 & 1 & 110 & 45 & 1 & 100 & 95 & 95 \\
\hline 2 & 1 & 110 & 60 & 1 & 76 & 73 & 73 \\
\hline 4 & 1 & 100 & 60 & 1 & 100 & 92 & 92 \\
\hline 5 & 1 & 100 & 60 & 0.5 & 62 & 59 & 59 \\
\hline 6 & 1 & 90 & 60 & 1 & 100 & 96 & 96 \\
\hline 9 & 1 & 80 & 75 & 1 & 100 & 97 & 97 \\
\hline 10 & 1 & 80 & 90 & 1 & 67 & 65 & 65 \\
\hline 11 & 0.5 & 80 & 75 & 1 & 100 & 96 & 192 \\
\hline 12 & 0.25 & 80 & 75 & 1 & 10 & 95 & 380 \\
\hline 13 & 0.1 & 80 & 75 & 1 & 62 & 60 & 603 \\
\hline 14 & 0.05 & 100 & 60 & 2 & 80 & 62 & 62 \\
\hline
\end{tabular}

${ }^{a}$ Rxn. condition: acetophenone ( $2 \mathrm{mmol}$ ), i-PrOH (solvent, $10 \mathrm{~mL}$ ), base (NaOH). ${ }^{b}$ Determined by GC-MS spectroscopy. ${ }^{c}$ nickel-aluminium alloy purchased from Lancaster (10034177) was applied. 
Table 2 Catalytic transfer hydrogenation reactions of various aromatic carbonyl compounds with $\mathrm{NiamSiO}_{2}{ }^{a}$

Entry Compound

Conv. (\%)

Sel. $(\%)$

Yield (\%)

1

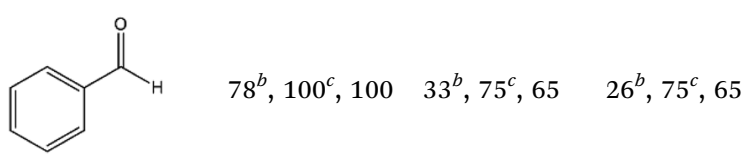

2<smiles>CCC(=O)c1ccccc1</smiles>

\section{$54,68^{d}, 44^{e}$}

$92,97^{d}, 100^{e}$

$50,66^{d}, 44^{e}$

3<smiles>CC(=O)c1ccc2ccccc2c1</smiles>

73<smiles>CC(=O)c1cccc2ccccc12</smiles><smiles>COc1ccc(C(C)=O)cc1</smiles>

6<smiles>CC(=O)c1ccc(C)cc1</smiles>

$40,45^{e}$

$34,56^{d}$

$55,67^{e}$

8<smiles>CC(=O)c1ccc(F)cc1</smiles>

9<smiles>CC(=O)c1ccccc1Br</smiles>

10<smiles>CC(=O)c1cccc(Br)c1</smiles>

\section{$78,99^{e}$}

55<smiles>CC(=O)c1ccc(Br)cc1</smiles>

$69,93^{e}$<smiles>CC(=O)c1ccccc1Cl</smiles>

$75,95^{e}$

$71,95^{e}$ $96,97^{e}$

$76,57^{e}$

61

$93,93^{d}$

$32,52^{d}$

$$
57,55^{d} \quad 31,35^{d}
$$

$88,97^{f}$

7, $34^{f}$

$97,93^{e}$

$39,42^{e}$

(1)

$42,38^{e}$

34

$95,100^{e} \quad 66,96^{e}$

$64,84^{e} \quad 48,79^{e}$

$78,97^{e} \quad 56,92^{e}$
14

Table 2 (Contd.)

\begin{tabular}{llll}
\hline Entry Compound & Conv. (\%) & Sel. (\%) & Yield (\%) \\
\hline
\end{tabular}

$63,91^{e}$

$64,53^{e}$

$40,48^{e}$

${ }^{a}$ Cat. (0.25 mol\%), base $\mathrm{NaOH}\left(1\right.$ eq.), rxn. temp. $80{ }^{\circ} \mathrm{C}$, rxn. time $75 \mathrm{~min}$, determined by GC-MS spectroscopy. ${ }^{b}$ Rxn. time $15 \mathrm{~min}$. ${ }^{c}$ Rxn. time 30 min. ${ }^{d}$ Rxn. time 2 h. ${ }^{e}$ Rxn. time 3 h. ${ }^{f}$ Rxn. temp. $100{ }^{\circ} \mathrm{C}$.

time dramatically (Entries 1, 2, 4, 6-10, Table 1). The rate of conversion increased as the temperature was increased. When

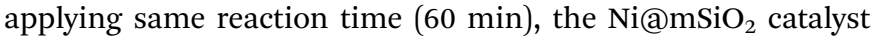
showed completed conversion at 90 and $100{ }^{\circ} \mathrm{C}$ (Entries 2, 4, 6, 8 , Table 1). Above $90{ }^{\circ} \mathrm{C}$, over $90 \%$ 1-phenylethanol was obtained within $1 \mathrm{~h}$ (Entries 1, 4, 6, Table 1). However, the conversion was decreased when the reaction was carried out at $110^{\circ} \mathrm{C}$ from 45 to $60 \mathrm{~min}$, and $80^{\circ} \mathrm{C}$ from 75 to $90 \mathrm{~min}$ (Entries $1,2,9,10$, Table 1 ). At $80{ }^{\circ} \mathrm{C}$, the progress of the reaction was monitored at every 15 min time interval (Entries 7-10, Table 1). The optimum time was found to be 75 min (Entry 10, Table 1).

Furthermore, the amount of catalyst was optimized. The amount of catalyst was $0.25 \mathrm{~mol} \%$ and above all, acetophenone was fully converted to 1-phenylethanol with 1 equivalent of base for $75 \mathrm{~min}$ (Entries 9, 11, 12, Table 1). Under 60\% of yield, lower conversions were attained with the addition of a small amount of Ni@mSiO ${ }_{2}$ (Entries 13, 14, Table 1). Regardless of the slight difference of selectivity of 1-phenylethanol, no further increase in the yield after $0.25 \mathrm{~mol} \%$ was observed. Thus, it is concluded that $0.25 \mathrm{~mol} \%$ is the optimum amount of catalyst (Entry 12, Table 1).

It was already mentioned that under the optimum conditions, the $\mathrm{Ni@mSiO}{ }_{2}$ system provided an outstanding yield of $95 \%$, following a good TON of 380 . It exhibits higher TON compared to other heterogeneous nickel nanocatalysts including our previous article. ${ }^{6,15,35}$ The optimized conditions were applied to extend the scope.

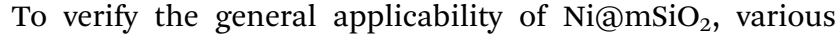
aromatic ketones were tested (Table 2). Compared to acetophenone, most of the compounds were reduced to alcohol

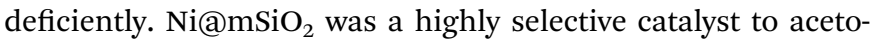
phenone. Thus we adjusted the reaction time longer excluding benzaldehyde (Entry 1, Table 2). Benzaldehyde was reduced to benzyl alcohol with only $65 \%$ yield under the optimized condition, although full conversion was attained. Benzaldehyde, which has higher reducibility, needed a shorter time to obtain higher yield (30 min). The low yield resulted from low selectivity and the fact that aldehyde easily reacts with alcohols, like a nucleophilic aromatic addition. The result of propiophenone was opposite to that of benzaldehyde (Entry 2, Table 2). Owing to electronic and steric interaction, propiophenone exhibited lower conversion compared to benzaldehyde. However, it showed outstanding selectivity with increasing 
time. A similar behavior was exhibited by 2-acetonaphthone; however, the gap in selectivity made a big difference yield (Entry 3 , Table 2). Next, we investigated the effect of additional functional groups on the aromatic ring. According to the electrondonating or withdrawing character, we achieved unique outcomes. The aromatic ketone containing electron-donating groups disfavored the reaction in low conversion under standard reaction conditions (Entries 5-7, Table 2). On the other hand, they had superior selectivity. The substituted acetophenone with electron-withdrawing groups continued with a better conversion, although subordinate selectivity, compared to those with electron-donating groups (Entries 8-13, Table 2). Among the activated acetophenones, 4-methoxyacetophenone exhibited the lowest conversion and showed no further increase in yield via high temperature (Entry 5, Table 2). Together with the para-iodo compound, bromoacetophenone derivatives successfully received hydrogen atoms from isopropyl alcohol in a 96\% yield for $3 \mathrm{~h}$ (Entries 10, 11, 13, Table 2). The steric factor of functional groups was also considered in this case. Because of its bulkiness, the ortho-substituted acetophenone had the lowest conversion (Entry 9, Table 2). Cyclohexanone, a sort of aliphatic ring, reduced to the corresponding alcohols, reaching up to $50 \%$ yield within $3 \mathrm{~h}$ (Entry 14, Table 2). Moreover, $\mathrm{Ni@mSiO} \mathrm{m}_{2}$ nanocatalyst shows highly catalytic activity compared with other Ni- and Ru-based catalysts previously reported (Table $\mathrm{S} 1 \dagger){ }^{36-43}$

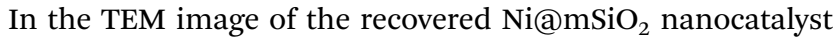
shown totally collapsed silica structure and sintering nickel nanoparticles (Fig. S5a and $\mathrm{b} \dagger$ ). In the stability of structure, silica was occurred procreated due to the steam during the

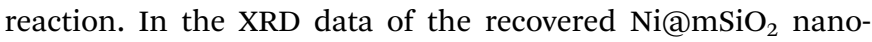
catalyst showed sharp peaks (Fig. S5c $\dagger$ ). It means reflected the increased crystal size. In addition, metallic nickel phase changed nickel silicide and nickel carbide during the reaction.

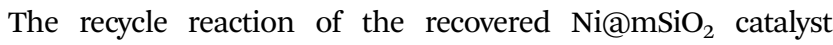
showed a low conversion (79\%) compared high conversion (100\%)

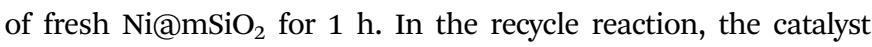
exhibited lower performance due to metallic nickel was changed no active site catalyst such as nickel carbide and nickel silicide.

\section{Conclusions}

In conclusion, we could newly synthesize highly dispersed nickel nanoparticles on mesoporous silica nanospheres, using melt infiltration process and subsequent thermal reduction. Based on the high particle dispersion of $36.3 \%$, the $\mathrm{Ni@mSiO}$ nanocatalyst showed superior catalytic performance compared to commercial nickel-aluminium alloy for transfer hydrogenation reactions of acetophenone. Furthermore, the optimized

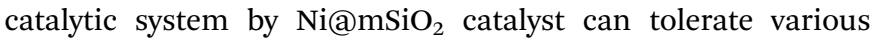
ranges of functional groups.

\section{Conflicts of interest}

There are no conflicts to declare.

\section{Acknowledgements}

This research was supported by Basic Science Research Program through the National Research Foundation of Korea (NRF) funded by the Ministry of Science, ICT \& Future Planning (NRF2017R1A4A1015533 and NRF-2017R1D1A1B03036303). J. C. Park was supported by the Research and Development Program of the Korea Institute of Energy Research (KIER) (No. B9-246101).

\section{Notes and references}

1 D. A. Evans, S. G. Nelson, M. R. Gagne and A. R. Muci, J. Am. Chem. Soc., 1993, 115, 9800-9801.

2 E. J. Corey and C. J. Helal, Tetrahedron Lett., 1996, 37, 56755678.

3 S. Gladiali and E. Alberico, Chem. Soc. Rev., 2006, 35, 226236.

4 F. Alonso, Nickel Nanoparticles in the Transfer Hydrogenation of Functional Groups, in Met. Nanoparticles Catal. Adv. Appl., The Royal Society of Chemistry, 2014, ch. 5, pp. 83-98.

5 D. Wang and D. Astruc, Chem. Rev., 2015, 115, 6621-6686.

6 J. Xiong, H. Shen, J. Mao, X. Qin, P. Xiao, X. Wang, Q. Wu and Z. Hu, J. Mater. Chem., 2012, 22, 11927.

7 R. C. Mebane, K. L. Holte and B. H. Gross, Synth. Commun., 2007, 37, 2787-2791.

8 G. P. Boldrini, D. Savoia, E. Tagliavini, C. Trombini and A. Umani-Ronchi, J. Org. Chem., 1985, 50, 3082-3086.

9 G. Xanthopoulou, O. Thoda, E. D. Metaxa, G. Vekinis and A. Chroneos, J. Catal., 2017, 348, 9-21.

10 Y. Du, H. Chen, R. Chen and N. Xu, Appl. Catal., A, 2004, 277, 259-264.

11 P. Fouilloux, Appl. Catal., 1983, 8, 1-42.

12 F. Alonso, P. Riente and M. Yus, Tetrahedron, 2008, 64, 18471852.

13 S. Z. Tasker, E. A. Standley and T. F. Jamison, Nature, 2014, 509, 299.

14 F. Alonso, P. Riente, J. A. Sirvent and M. Yus, Appl. Catal., A, 2010, 378, 42-51.

15 D. Kim, H. Kang, H. Park, S. Park, J. C. Park and K. H. Park, Eur. J. Inorg. Chem., 2016, 3469-3473.

16 J. C. Park, H. J. Lee, J. Y. Kim, K. H. Park and H. Song, J. Phys. Chem. C, 2010, 114, 6381-6388.

17 K. Shimura and K. Shimizu, Green Chem., 2012, 14, 29832985.

18 H. Woo, K. Lee, J. C. Park and K. H. Park, New J. Chem., 2014, 38, 5626-5632.

19 P. E. de Jongh and T. M. Eggenhuisen, Adv. Mater., 2013, 25, 6672-6690.

20 T. M. Eggenhuisen, J. P. den Breejen, D. Verdoes, P. E. de Jongh and K. P. de Jong, J. Am. Chem. Soc., 2010, 132, 18318-18325.

21 P. Munnik, P. E. de Jongh and K. P. de Jong, Chem. Rev., 2015, 115, 6687-6718.

22 J. I. Kwon, T. Kim, J. C. Park, J.-I. Yang and K. Y. Lee, J. Nanosci. Nanotechnol., 2016, 16, 1787-1792. 
23 X. Liu, J. G. Khinast and B. J. Glasser, Ind. Eng. Chem. Res., 2014, 53, 5792-5800.

24 F.-S. Xiao, S. Zheng, J. Sun, R. Yu, S. Qiu and R. Xu, J. Catal., 1998, 176, 474-487.

25 M. Kim, J. C. Park, A. Kim, K. H. Park and H. Song, Langmuir, 2012, 28, 6441-6447.

26 B. G. Johnson, S. Raynor, D. Shephard, J. Thomas and M. Mantle, Chem. Commun., 1999, 1167-1168.

27 T. Maschmeyer, F. Rey, G. Sankar and J. M. Thomas, Nature, 1995, 378, 159.

28 H. Takahashi, B. Li, T. Sasaki, C. Miyazaki, T. Kajino and S. Inagaki, Microporous Mesoporous Mater., 2001, 44, 755762.

29 Y. Wang, D. Wang, M. Tan, B. Jiang, J. Zheng, N. Tsubaki and M. Wu, ACS Appl. Mater. Interfaces, 2015, 7, 26767-26775.

30 J. S. M. Samec, J.-E. Backvall, P. G. Andersson and P. Brandt, Chem. Soc. Rev., 2006, 35, 237-248.

31 F. Alonso, P. Riente and M. Yus, Tetrahedron Lett., 2008, 49, 1939-1942.

32 J. Clayden, N. Greeves, S. Warren and P. Wothers, "Organic Chemistry", 2001, (n.d.).

33 M. Yamakawa, H. Ito and R. Noyori, J. Am. Chem. Soc., 2000, 122, 1466-1478.

34 R. L. Chowdhury and J.-E. Backvall, J. Chem. Soc., Chem. Commun., 1991, 1063-1064.

35 A. F. Trasarti, N. M. Bertero, C. R. Apesteguía and A. J. Marchi, Appl. Catal., A, 2014, 475, 282-291.

36 N. Catellanos-Blanco, A. Arévalo and J. J. García, Dalton Trans., 2016, 45, 13604.
37 Y. Li, S. Yu, W. Shen and J. Gao, Acc. Chem. Res., 2015, 48, 2587-2598.

38 P. Yang, L. H. Lim, P. Chuanprasit, H. Hirao and J. S. Zhou, Angew. Chem., Int. Ed., 2016, 55, 12083-12087.

39 B. J. Simmons, M. Hoffmann, J. Hwang, M. K. Jackl and N. K. Grag, Org. Lett., 2017, 19, 1910-1913.

40 S. Guo, P. Yang and J. S. Zhou, Chem. Commun., 2015, 51, 12115-12117.

41 R. Liu, T. Cheng, L. Kong, C. Chen, G. Liu and H. Li, J. Catal., 2013, 307, 55-61.

42 Z. Cao, H. Qiao and F. Zeng, Organometallics, 2019, 38, 797804.

43 S. Guillarme, T. X. M. Nguyen and C. Saluzzo, Tetrahedron: Asymmetry, 2008, 19, 1450-1454.

44 S. Iyer and A. Sattar, Synth. Commun., 1998, 28, 1721-1725.

45 V. Polshettiwar, B. Baruwati and R. S. Varma, Green Chem., 2009, 11, 127-131.

46 M. D. Le Page and B. R. James, Chem. Commun., 2000, 16471648.

47 S. Iyer and J. P. Varghese, J. Chem. Soc., Chem. Commun., 1995, 4, 465-466.

48 W. N. O. Wylei, A. J. Lough and R. H. Morris, Organometallics, 2009, 28, 6755-6761.

49 B. Saes, D. G. A. Verhoeven, M. Lutz, R. J. M. Gebbink and M.-E. Moret, Organometallics, 2015, 34, 2710-2713.

50 P. Phukan and A. Sudalai, Synth. Commun., 2015, 30, 24012405.

51 F. Foubelo, C. Nájera and M. Yus, Tetrahedron: Asymmetry, 2015, 26(15-16), 769-790. 